\title{
Insect Olfactory Neurons in vitro: Morphological and Immunocytochemical Characterization of Male-Specific Antennal Receptor Cells from Developing Antennae of Male Manduca sexta
}

\author{
Monika Stengl and John G. Hildebrand \\ Arizona Research Laboratories, Division of Neurobiology, University of Arizona, Tucson, Arizona 85721
}

\begin{abstract}
Sex-pheromone components released by Manduca sexta females are detected solely by male-specific olfactory receptor neurons that innervate long sensilla trichodea on the male antennae. To facilitate studies of the development and physiology of these receptor cells, we have produced primary in vitro cultures of cells dissociated from pupal male antennae. These cultures comprise several morphological types of cells, 2 of which have been characterized immunocytochemically with a pair of monoclonal antibodies that were shown previously to recognize certain antigens in olfactory receptor neurons at defined stages of development. The good correlation between in vivo and in vitro expression of these antigens suggests that the immunocytochemically recognized cells are olfactory receptor neurons that follow at least partially their normal course of differentiation in vitro.
\end{abstract}

Female Manduca sexta moths attract conspecific males by re leasing a specific sex-pheromone blend from glands in the terminal abdominal segments (Starratt et al., 1979; Tumlinson et al., 1989). The pheromone components stimulate sexually dimorphic olfactory receptor neurons (ORNs), which innervate long sensilla trichodea found only on the male antennal flagellum (Sanes and Hildebrand, 1976a, b; Schweitzer et al., 1976; Kaissling et al., 1989). A pheromone-responsive trichoid sensillum comprises 2 sensory neurons and at least 4 associated cells, the hairshaft-forming trichogen cell, the socket-forming tormogen cell, the thecogen cell, and a glial cell (Sanes and Hildebrand, 1976b; Keil, 1984; Keil and Steinbrecht, 1984, 1987; Steinbrecht and Gnatzy, 1984; Keil, 1989). The thecogen cell smooth-

\footnotetext{
Received July 6, 1989; revised Sept. 7, 1989; accepted Sept. 14, 1989.

We thank Dr. Akira Hishinuma for providing purified antibodies and hybridoma supernatants essential to this project. We are very grateful to Dr. Jon $\mathrm{H}$. Hayashi for invaluablc contributions to the progress of this work. Dr. Steven G. Matsumoto generously provided nerve growth factor, as well as masterful advice about cell culture. We also thank Drs. Danny Brower, Marcie Glicksman, Uwe Homberg, Lynne A. Oland, Don Sakaguchi, and Leslie P. Tolbert for technical advice; Dr. Thomas Keil for helpful discussions about the identification of different antennal cell types; Charles Hedgcock for photographic assistance; Galya Orr and Anastasia Peterson for materials and help; Drs. Jon Hayashi, Uwe Homberg Richard B. Levine, Camilla Strausfeld, and Leslie P. Tolbert for valuable comments on the manuscript; and Deborah Sakiestewa and Peggy Randolph for expert assistance with insect rearing. Drs. James Buckner and James Svoboda of the USDA generously supplied $M$. sexta eggs, and Dr. Dwight Lynn (USDA) kindly gave us the $M$. sexta cell line, as well as information about maintaining it. This research was supported by a grant from Monsanto Company and by NIH grant AI-23253.

We dedicate this paper to the memory of our friend and colleague Laura $M$. Griffin.

Correspondence should be addressed to Dr. John G. Hildebrand, ARL Division of Neurobiology, 611 Gould-Simpson Building, University of Arizona, Tucson, AZ 85721 .

Copyright (C) 1990 Society for Neuroscience $0270-6474 / 90 / 030837-11 \$ 02.00 / 0$
}

ly covers the somata of the ORNs, and the glial ccll cnwraps their axons (Keil, 1984). Because of their small size and the closely apposed supporting cells, the ORNs in situ are not amenable to experiments involving intracellular or patch-clamp recording methods.

To study the physiology and development of the responses of the ORNs to odors, we have developed procedures for the long-term primary cell culture of these cells dissociated from antennal flagella of male $M$. sexta pupae. To identify the ORNs and to distinguish them from other types of cells in the antennal cultures, we used 2 specific monoclonal antibodies (Hishinuma et al., 1988a, b): olfactory-specific antibody (OSA) and male olfactory-specific antibody (MOSA).

Development of $M$. sexta, from the egg through eclosion of the adult moth, takes $42-49 \mathrm{~d}$. $M$. sexta passes through 5 larval instars, in all accounting for about $14 \mathrm{~d}$, and a pupal period, in which adult development normally takes 18-21 d (Tolbert et al., 1983). OSA recognizes ORNs when they start to grow processes at late stage 3 of adult development (about 3-6 d after the larval-pupal molt at $26^{\circ} \mathrm{C}$ ). MOSA binds to non-neural cells lacking processes in the lumen of the early pupal antenna (stages 1-6) and recognizes male-specific ORNs when they become responsive to pheromone components at the end of pupal-adult development, stage 17 (17-35 d after the larval-pupal molt at $26^{\circ} \mathrm{C}$ ). We found a good correlation between the timing and specificity of the in vitro and in situ expression of OSA and MOSA immunoreactivity in subsets of cells cultured from developing antennae.

The primary cell culture system described here thus appears to be promising for studies of the development and physiology of antennal ORNs from $M$. sexta. A preliminary account of some of this work has been presented elsewhere (Stengl and Hildebrand, 1988).

\section{Materials and Methods}

\section{Animals}

Manduca sexta (Lepidoptera:Sphingidae) were reared from eggs on artificial diet (modified from Bell and Joachim, 1976) on a long-day photoperiod regimen $(17 \mathrm{hr}$ light $/ 7 \mathrm{hr}$ dark $)$ at $26^{\circ} \mathrm{C}$ and $50-60 \%$ relative humidity. Pupae were staged as previously described (Sanes and Hildebrand, 1976a; Tolbert et al., 1983). They were usually selected for dissection between 2:00 and 5:00 AZT (Arbitrary Zeitgeber Time with lights-on at 00:00 AZT) and anesthetized by chilling on ice for 10-15 min before dissection to isolate the antennal flagellum.

\section{Cell cultures}

Unless otherwise specified, all culture media were purchased from Gibco (Grand Island, NY) and all chemicals and biochemicals from Sigma Chemical Co. (St. Louis, MO). 
Antennal flagella from late stage- 2 male pupae were disrupted by a combination of trituration with a Pasteur pipette and enzymatic treatments in papain $(1 \mathrm{mg} / \mathrm{ml})$ Hanks' Balanced Salt Solution (HBSS). After 20-120 min in the enzyme solution, the dispersed cells were collected and washed (to terminate enzymatic activity by dilution) by centrifugation twice for $8 \mathrm{~min}$ at $1000 \mathrm{rpm}$ in L15 supplemented with $5 \%$ fetal bovine serum (LFBS). The pellet containing dispersed antennal cells was resuspended in L15 medium, and aliquots were plated on uncoated Falcon plastic dishes (diameter, $3.5 \mathrm{~cm}$ ) or concanavalin A (Con A)coated coverslips in LFBS ( $374 \mathrm{mOsm}$ ) supplemented with conditioned media or hormones. The cultures could be maintained for more than a month at $29^{\circ} \mathrm{C}$ in an incubator at high humidity and with normal air.

These culture conditions were selected because they best supported the survival and growth of cells that could be recognized by OSA. To arrive at these conditions, we tested the following variations of dispersal methods, substrates, and media.

Dispersal. Antennal tissue was treated with various types and grades of collagenase, Dispase (Boehringer/Mannheim), pancreatin, papain, and trypsin, as well as several mixtures of collagenase and Dispase. The concentrations of enzymes tested ranged from $20 \mu \mathrm{g} \mathrm{to} 0.1 \mathrm{gm} / \mathrm{ml}$, and the exposure times, from $3 \mathrm{~min}$ to $8 \mathrm{hr}$. Papain was chosen for routine use because it yielded dispersed, viable neuronlike cells without destroying most of the antennal tissue. With the other enzymes tested, the tissue could not be disrupted into dispersed cells without killing most of them.

Substrates. Growth substrates that were tested included various types of collagen, fibronectin, laminin, poly-L-ornithine, poly-L-lysine, polyethyleneglycol, agar, wheat germ agglutinin, and Con A; glass; plastic (dishes) from Corning (Houston, TX) and Falcon (Becton Dickinson Labware, Oxnard, CA); cell-TAK (Bio Polymers Inc., Farmington, CA); and basement membrane-derived Matrigel (Collaborative Research, Lexington, MA). Except for Con $A$ and one kind of Falcon plastic (culture dishes \#3001), none of these surfaces supported the adhesion and differentiation of cells that were recognized by OSA.

Media. Screening for an effective culture medium involved testing various combinations of Grace's, Schneider's, L15, DMEM, and NUserum (Collaborative Research, Lexington, MA) media. L1 5 was chosen because it best supported the growth of the neuronlike cells (recognized by OSA) and fewer non-neuronal cells (characterized by morphological criteria). Because Grace's medium favored the growth of non-neuronal cells over neuronlike cells, it was used to support the high-density, mostly non-neural cell cultures needed to produce conditioned medium. The ionic concentrations of the different stock media were varied by addition of $\mathrm{KCl}$ (to a maximum concentration of $200 \mathrm{~mm}$ ). About 20 $\mathrm{mM} \mathrm{KCl}$ was found to favor growth of neuronlike cells in vitro, while $200 \mathrm{~mm} \mathrm{KCl}$ resulted in their death within $1-2 \mathrm{~d}$.

A new medium was designed (in collaboration with Dr. J. Hayashi) with the ionic concentrations of L15 medium and the additional, nonionic constituents of Grace's medium. In addition, different supplements were tested at various concentrations: murine nerve growth factor (NGF; donated by Dr. S. Matsumoto), epidermal growth factor (EGF, Collaborative Research, Lexington, MA), fetal bovine serum, insulintransferrin-sodium selenite, and 20-hydroxyecdysone. We also tested conditioned media, including supernatant fractions from non-neuronal antennal cell cultures (see above), from a $M$. sexta cell line (Eide et al., 1975; MRRL-CH1 cells originally provided by Dr. D. Lynn and generously supplied to this project by Drs. J. Hayashi and L. Oland), from fat-body cultures, from antennal-lobe cultures, and from antennal homogenates, as well as extracellular fluid from developing antennal flagella. Of these supplements, only the conditioned media from nonneuronal antennal cells, the $M$. sexta cell line, extracellular fluid from antennae, and 20 -hydroxyecdysone (ca. $1 \mu \mathrm{g} / \mathrm{ml}$ ) prolonged the survival of the neuronlike cells. The media were tested at osmolarities between 300 and 500 mOsm, adjusted with mannitol. The optimal osmolarity for long-term survival of the antennal cell cultures proved to be 370 mOsm. Attempts to culture dispersed ORNs in the absence of conditioned media and other types of cells failed, and the isolated ORNs died within about $2 \mathrm{~d}$.

\section{Immunocytochemistry}

For immunocytochemical staining of the cultures with OSA and MOSA (Hishinuma et al., 1988a, b), the growth medium was removed with several washes in HBSS. The cultures were fixed for $30 \mathrm{~min}$ in $4 \%$ paraformaldehyde and then washed over a period of $1 \mathrm{hr}$ with 6 changes of dilution buffer (PBS, pH 7.4, 3\% normal goat serum (NGS), with or without $0.1 \%$ Triton $\mathrm{X}-100$ ). The cultures were preincubated for $2 \mathrm{hr}$ in dilution, incubated for about $14 \mathrm{hr}$ with primary antibody, and then washed in 3 changes of dilution buffer for $10 \mathrm{~min}$ each. After incubation in dilution buffer for $\geq 2 \mathrm{hr}$, the secondary antibody (goat anti-mouse IgG, rhodamine-coupled) was added for $1 \mathrm{hr}$ at a dilution of 1:60. The cultures were washed in several changes of dilution buffer for $\geq 30 \mathrm{~min}$ and then embedded in glycerol. The stained cultures were observed and photographed with a Zeiss inverted fluorescence microscope. The stained cells were photographed on Kodak Tri-X Pan 400 or Technical Pan $2415 \mathrm{film}$. As negative controls, cultures of dispersed cells from antennal lobes, for more than 20 experiments (generously supplied by Dr. J. Hayashi and Ms. G. Orr; Hayashi and Hildebrand, 1988, 1990), or from whole brains ( 5 experiments) were used instead of the antennal cultures. Moreover, 2 control experiments were performed with stage- 3 female antennae. In addition, the immunocytochemical protocol was followed without application of the primary antibody or, for MOSA staining, without Triton X-100. Sections of the antennal flagellum at different stages of adult development served as positive controls, as did cultures of cells from pupal stage- 4 antennae, in which the antigens recognized by OSA and MOSA are expressed in vivo.

\section{Direct coupling of fluorescence labels to purified OSA and MOSA}

Affinity-purified monoclonal antibodies (provided by Dr. A. Hishinuma) were lyophilized overnight, resuspended in distilled water to a final concentration of $1.6 \mathrm{mg}$ protein $/ \mathrm{ml}$, and dialyzed against $0.1 \mathrm{M} \mathrm{Na}$ borate buffer ( $\mathrm{pH} \mathrm{10}$ ) for $2 \mathrm{~d}$. Monoclonal antibody (ca. $1 \mathrm{mg} / \mathrm{ml}$ borate buffer) was incubated on a shaker with $100 \mathrm{gm}$ tetra-rhodamine-isothiocyanate (Molecular Probes, Fugene, OR) in dimethylformamide or with 60 gm fluorescein-5-isothiocyanate (FITC; Molecular Probes, Eugene, OR) for $2 \mathrm{hr}$ at room temperature and then at $4^{\circ} \mathrm{C}$ for $12 \mathrm{hr}$. The rhodamine-coupled OS $\Lambda$ and the FITC-coupled MOSA were separated from unlabeled antibodies and labeling reagents by passage through a Sephadex G-50-80 column (bead size, 20-80 m) in PBS.

\section{Other methods used to characterize different cell types in vitro}

Squash preparations of antennal-flagellar epidermal tissue at all stages of pupal-adult development were examined with the light microscope and compared. This permitted us to recognize different cell types in situ and to make observations about their functions in the antenna. Owing to their thickness, these preparations did not permit publication-quality photomicrography.

Antennal flagella of various developmental stages were disrupted by trituration and incubated with papain $(1 \mathrm{mg} / \mathrm{ml} \mathrm{HBSS})$ in a culture dish. During several hours of this enzymatic dispersion, the antennal cells were observed with the light microscope to examine associations between different cell types and changes in cell morphology during the dissociation procedure.

Finally, time-lapse photomicrography was used to follow changes in the shapes of different types of cells in vitro.

\section{Methods used to assess survival of different cell types in vitro}

Cells were judged to be alive, dying, or dead mainly on the basis of morphological criteria. A cell was "alive" if its soma was smooth and phase-bright and if it had growing processes that changed length and direction of growth within 1-2 hr. Such cells excluded Trypan blue and stained with diacetylfluorescein (Kodak). "Dying" cells developed vacuoles; their somata became granular to various extents, and their processes tended to detach from the substrate. Dying cells stained with diacetylfluorescein, and only a few of them took up Trypan blue. "Dead" cells did not take up diacetylfluorescein but did stain with Trypan blue and appeared to have a darkly granular soma.

\section{Results}

This report is based upon many more than 1000 experiments, in each of which 6 antennae were disrupted and their cells dispersed and distributed among and plated in (typically 21) culture dishes. After establishment of the culture conditions and development of the protocols for immunocytochemistry, ca. 98\% of such experiments were successful. An experiment was considered to be successful if the observer could easily identify at 

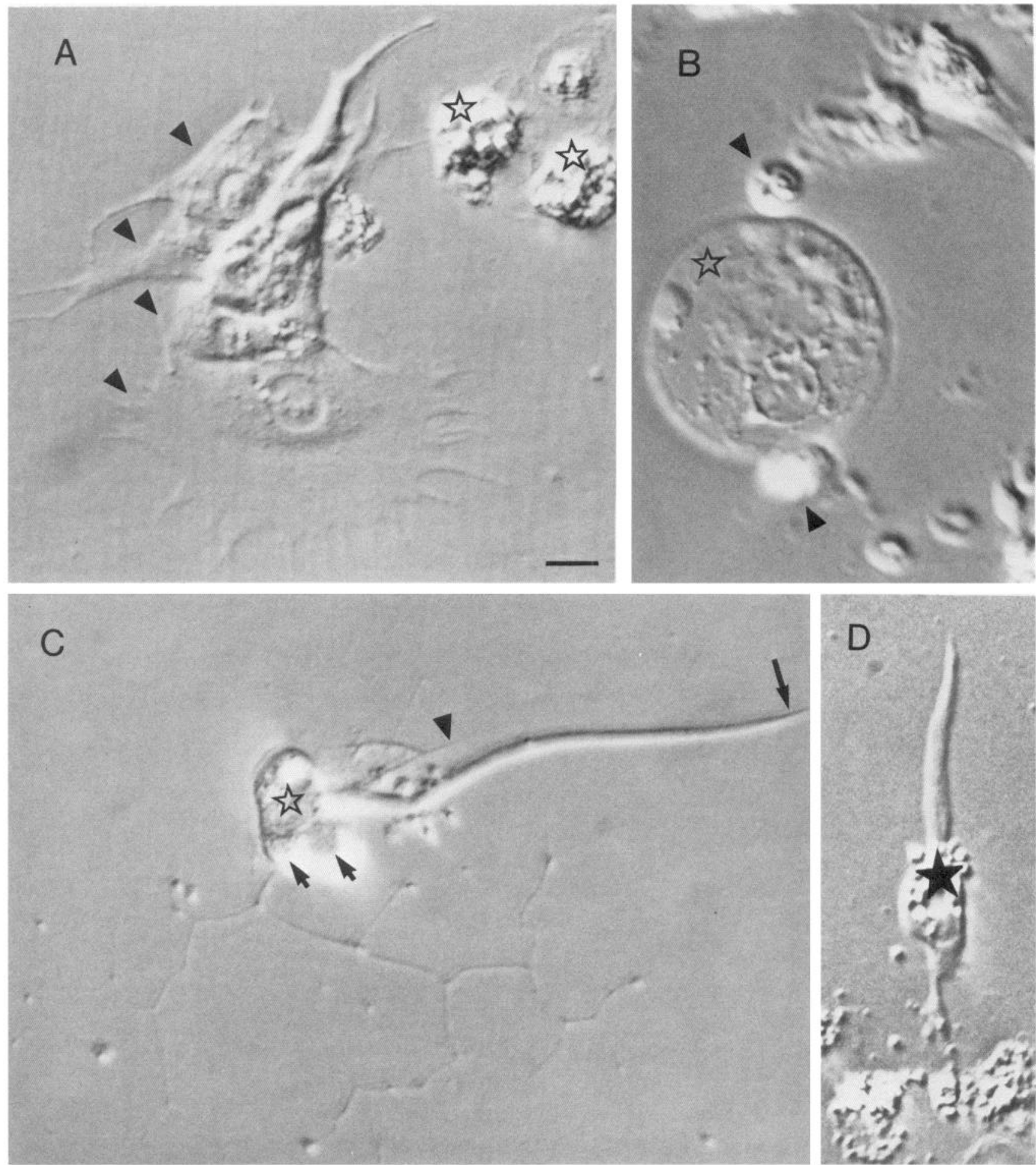

Figure 1. A, Two type-1 cells (stars) with granular surfaces and opaque cell bodies. The other cells (arrowheads) are type-3 cells, which form lamellipodia on the surface of the plastic culture dish. $B$, Translucent type- 2 cell (star), suspended in culture medium, contains many inclusions of different sizes. Attached to its surface and out of the plane of focus are cell-like particles (arrowheads). $C$, Two type-5 cells (short arrows) with fine processes are attached to the soma of a type-1 "hair"-forming cell (star). One process (arrowhead) detached from the plastic surface and started to grow along the "hairshaft" (long arrow). D, A "scale"-forming type-1 cell (star), which forms a shorter and broader shaft than the "hair"-forming type-1 cell, often with parallel ridges. Scale bar, $10 \mu \mathrm{m}$.

least 10 distinct, isolated, healthy-looking ORNs without covering supporting cells in each culture dish.

We established primary cultures of dispersed cells from antennae of stage- 2 male $M$. sexta pupae. Six antennae (from which the basal and tip segments had been cut off) were used in each experiment. At least 5 morphologically distinguishable types of cells survive and grow under the conditions selected for these cultures. Two of these cell types could be further specified with 
the help of 2 monoclonal antibodies (Hishinuma et al., 1988a, b).

\section{Cells without processes}

Type-1 cells (nontranslucent cells without processes). Figure $1 \mathrm{~A}$ shows cells of a type characterized by a granular surface and undiscernible nucleus in vitro when viewed with phase optics. In situ similar cells are the most numerous (ca. $60 \%$ of all discrete cells per culture dish) recognizable type in the outermost cell layer of the flagellum of stage- 2 pupae and grow on a continuous sheet of cells that have lamcllipodia (typc-3 cclls, scc below). Type- 1 cells were mostly round, with a diameter of 10$30 \mu \mathrm{m}$. In vitro they formed clusters with other types of cells, e.g., with type-3 cells and other unidentified cells that could secrete dark, cuticlelike deposits. Secretion of these deposits was favored by culturing cells at high density in Grace's medium containing 20-hydroxyecdysone.

Type-2 cells (translucent cells without processes). The translucent cell in Figure $1 B$ contained many particulate inclusions of various sizes. These cells (ca. $8 \%$ of all discrete cells per culture dish) were mostly round and floated in the medium or attached to Con A or to dying cells on the bottom of the plastic culture dishes. They appeared to increase in number during the first few days in vitro and formed clusters of various numbers of cells.

Unclassified cells without processes. Several other unidentified round cells of various sizes, and many decaying cell bodies that could not be further identified, could be found attached to the bottom of the culture dish or floating in the medium within the first hour after dispersion. Some of these cells, with a soma diameter of about $25 \mu \mathrm{m}$, could be stimulated by 20 -hydroxyecdysone to form processes that resembled sensory hairs (Fig. 1C). Sometimes a type-5 cell (with processes, see below) was found attached to one of these "trichoid" cells, extending one of its processes along the presumed hairshaft (Fig. $1 C$ ). In cultures about 1 week old, other cells that resembled differentiated scales could also be found in vitro (Fig. $1 D$ ). The appearance of "hairs" and "scales" in vitro depended on the level of 20-hydroxyecdysone. The differentiation of these cells was incomplete. Although the "hair" grew to be several hundred microns long, it never became fully culticularized.

\section{Cells with processes}

Type-3 cells (cells with lamellipodia). Figure $1 \mathrm{~A}$ shows flat cells with lamellipodia (ca. $25 \%$ of all discrete cells per culture dish). Some of these cells, highly variable in size and shape, appeared to multiply, adhere to each other, and form confluent sheets. Of the culture conditions tested (see Materials and Methods), Grace's medium on Falcon plastic surfaces best supported the growth of these cells, and they could be kept for more than a month in vitro. Type- 3 cells often appeared to be targets of processes of type- 5 cells and also to provide a favorable substrate for growth of type-1 cells. Some type-3 cells appeared to secrete a gelatinous material, which seemed to allow adhesion of other types of cells, such as type- 5 cells. In older cultures, type- 3 cells (still recognizable by virtue of their lamellipodia) formed spheres and complicated 3-dimensional scaffolds in the culture dishes (Fig. $2 A$ ). In spite of their dramatic changes in shape, these cells could still be recognized as type- 3 cells by immunocytochemistry and by light-microscopical observations of the same cells changing over time.

Type-4 cells (cells with bipolar or multipolar thick processes).
These cells (Fig. $2 B$; ca. $2 \%$ of all discrete cells per culture dish) had elongated somata with undiscernible nuclei and grew processes that were usually unbranched and several hundred microns long. Cells of this type could be kept for more than a month in vitro, grew better in Grace's than in L1 5 medium, and seemed to change little over time.

Type-5 cells (cells with fine processes). The somata of these cells (Fig. 3, $A, B$ ) were round or oval with diameters of 4-15 $\mu \mathrm{m}$. Most of the larger cells had a round, opaque cell body, while the smaller oval cells were translucent and exhibited a visible round nuclcus. These cells grew uni- or bipolar processes that could extend over several hundred microns with elaborate branching. Type-5 cells were sometimes found associated with the "hair"-forming cells (Fig. $1 C$, see above). Sometimes another unidentified cell (possibly a thecogen-like cell) started to grow over the soma of a type- 5 cell with fine processes. Type- 5 cells grew better in L15 medium than in mixtures of Grace's or Schneider's media and survived from $3 \mathrm{~d}$ to more than 4 weeks in vitro. About $5 \%$ of all discrete cells in a culture dish were type-5 cells. Depending upon plating density, from 10 to several hundreds of these ORN-like cells could be found in a single dish. Approximately $98 \%$ of these cells survived in culture at least 2-3 weeks.

For cultures maintained longer than 1 week, the medium was optimized for long-term survival of the type-5 cells and contained $1 \mu \mathrm{g} / \mathrm{ml} \mathrm{20-hydroxyecdysone} \mathrm{and} \mathrm{medium} \mathrm{conditioned}$ by the $M$. sexta cell linc. Under these conditions, type- 1 cells die, type-3 flat cells also show enhanced long-term survival, and type- 4 cells appear to be unchanged.

\section{Immunocytochemical characterization of antennal cells in culture}

Two ORN-specific monoclonal antibodies (Hishinuma et al., 1988a, b), olfactory-specific antibody (OSA) and male olfactoryspecific antibody (MOSA), were used to identify the ORNs in vitro and to test whether these cells express the corresponding cell-type-specific antigens in vitro according to a schedule similar to that observed in situ.

OSA-immunoreactive cells in vitro. OSA (Hishinuma et al., 1988a) recognized most $(\geq 80 \%)$ but not always all type- 5 cells with fine processes in vitro. The antibody stained the soma and the processes of the cells (Fig. $4, A, B$ ). The staining did not depend on the presence of Triton X-100 and became prominent in cultures derived from stage- 2 male pupal antennae, after $2 \mathrm{~d}$ in vitro. The immunoreactive staining was still specific for type- 5 cells after 4 weeks in vitro. In some cultures (of various ages), a few round cells with somata approximately $10 \mu \mathrm{m}$ in diameter and lacking processes were also OSA-immunoreactive. These cells were assumed to be ORNs that had not grown processes. This hypothcsis was strengthened by the fact that, in cell-attached and whole-cell patch-clamp experiments, these round cells exhibited membrane currents identical to those recorded in ORNs with processes (Stengl et al., 1989).

MOSA-immunoreactive cells in vitro. MOSA staining appeared only if the cultured cells were permeabilized with Triton X-100. In 1-d-old cultures, MOSA specifically stained many round translucent cells without processes (type-2 cells, Fig. 5, $A, B)$. The staining was still recognizable but less prominent in a few type- 2 cells in 4-week-old cultures. MOSA antigenicity was concentrated in granules that were distributed throughout the cell. Addition of 20-hydroxyecdysone to the culture medium did not affect the staining. In cultures 2-3 weeks old, MOSA 

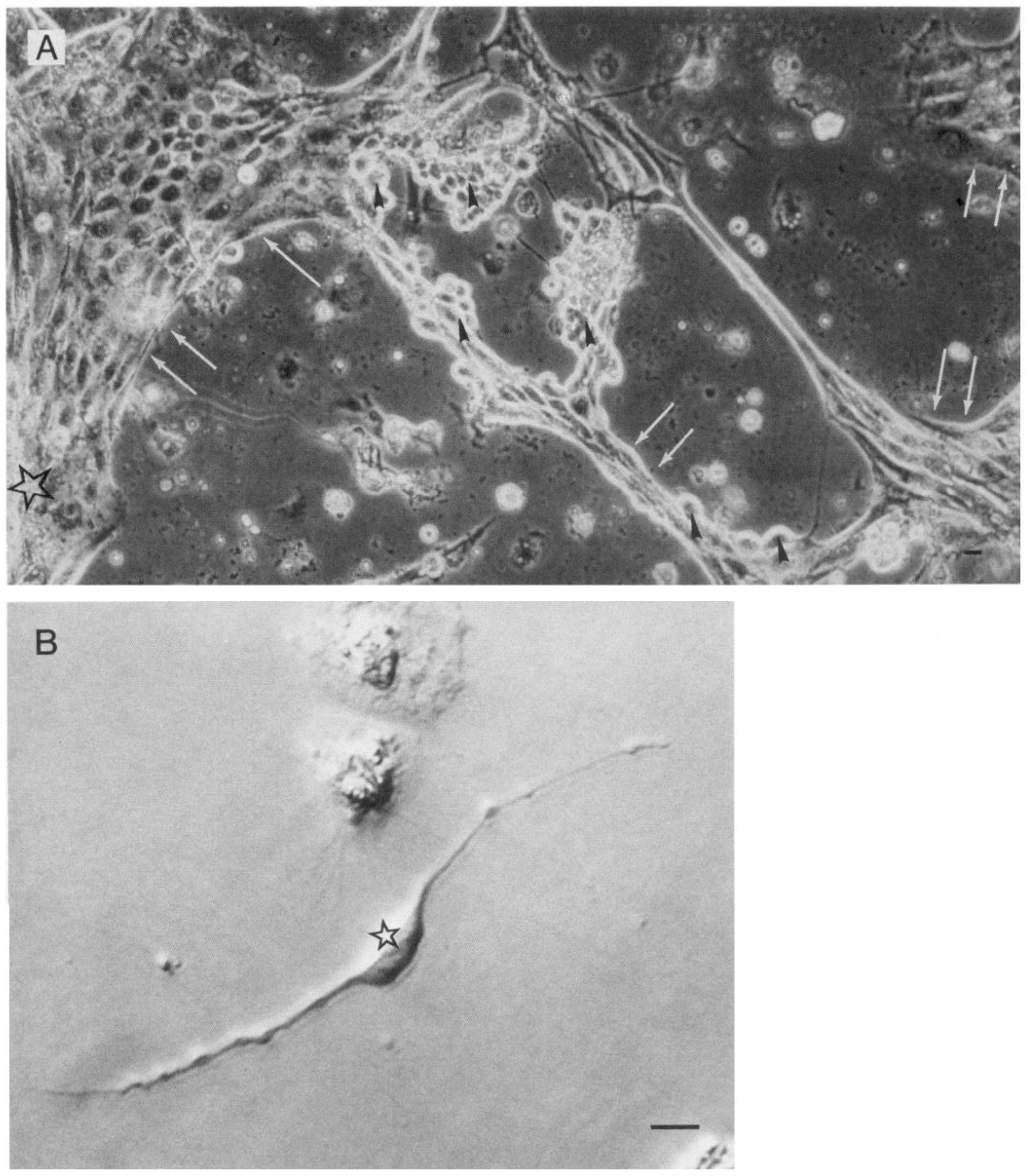

Figure 2. A, Many type-3 cells (some marked with white arrows) form continuous sheets, to which other cells attach. On the left, a cluster of type-1 cells is growing on the sheet of type-3 cells (star). Several round cells of unknown origin (some marked with arrowheads) also attach to the continuous layer of type- 3 cells. $B$, A type- 4 cell (star) that grew 2 thick, beaded processes after $2 \mathrm{~d}$ in culture. Its function in situ is unknown. Scale bars, $10 \mu \mathrm{m}$.

immunoreactivity appeared in a variable proportion of cells with fine processes (type-5 cells; Fig. $6, A, B$ ). The antibody apparently bound to a cytoplasmic antigen in the soma and processes of these cells. The MOSA immunoreactivity of type-5 cells was granular and accessible only after treatment with Triton $\mathrm{X}-100$ but was often less pronounced than that in the type- 2 cells. The MOSA immunoreactivity in type- 5 cells over 2 weeks old was expressed to a variable extent in cells with fine processes 

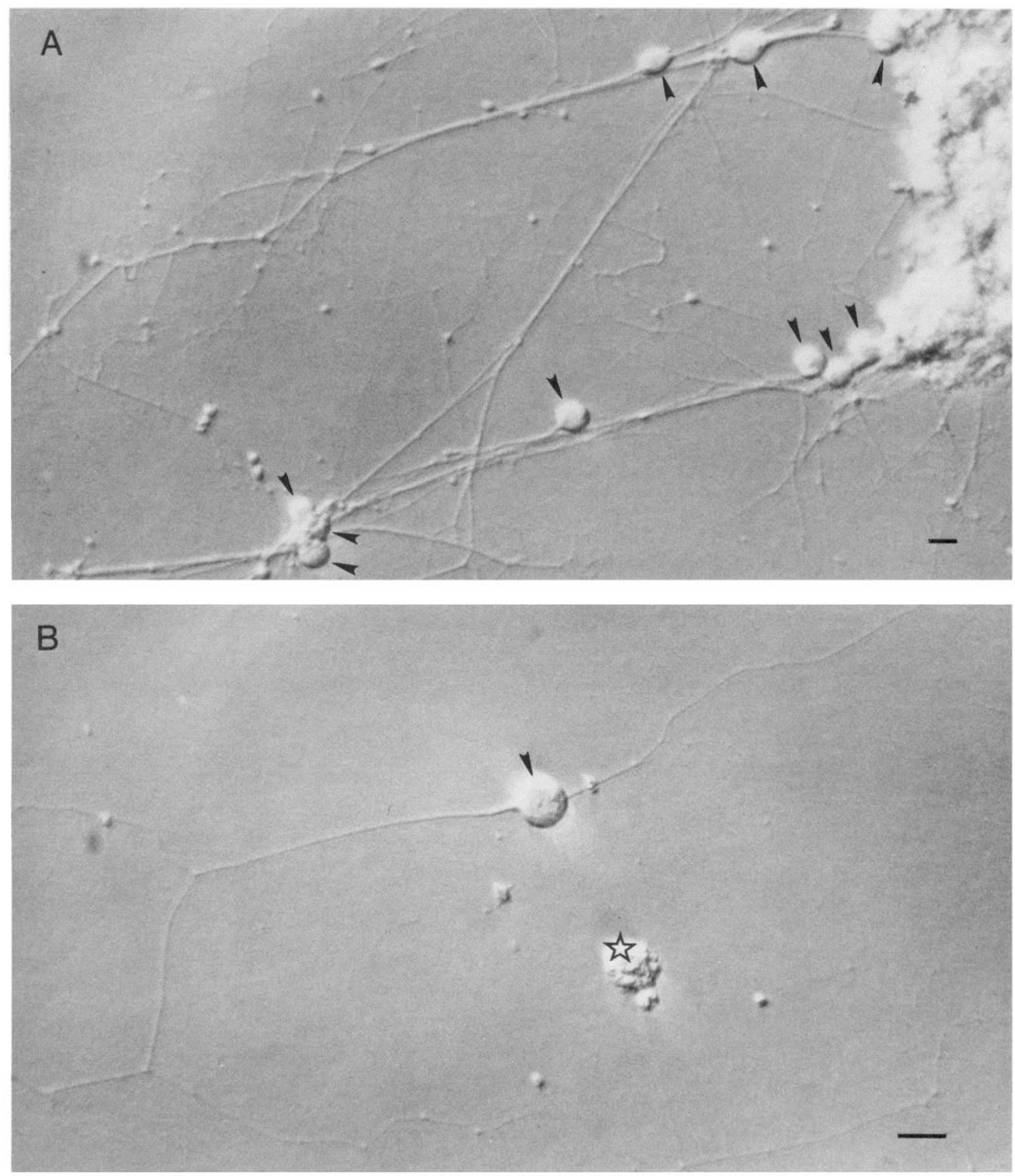

Figure. 3. A, Several bipolar type-5 cells (arrowheads). B, A bipolar type-5 cell with a round, opaque cell body (arrowhead) and fine, branching processes after $2 \mathrm{~d}$ in culture. Also shown is the decaying cell body of a type- 5 cell (star). Scale bars, $10 \mu \mathrm{m}$.

within a single culture dish (Fig. 6, $A, B$ ). MOSA-immunoreactive type- 2 cells, but not MOSA-immunoreactive type- 5 cells, were found in cultures of dispersed cells from female antennae.

Doubly immunoreactive cells. Double-labeling experiments, using rhodamine-conjugated OSA and FITC-conjugated MOSA, demonstrated that all of the MOSA-immunoreactive type- 2 cells were OSA-immunoreactive. All type-5 cells in older cultures that were MOSA-immunoreactive, however, were also 

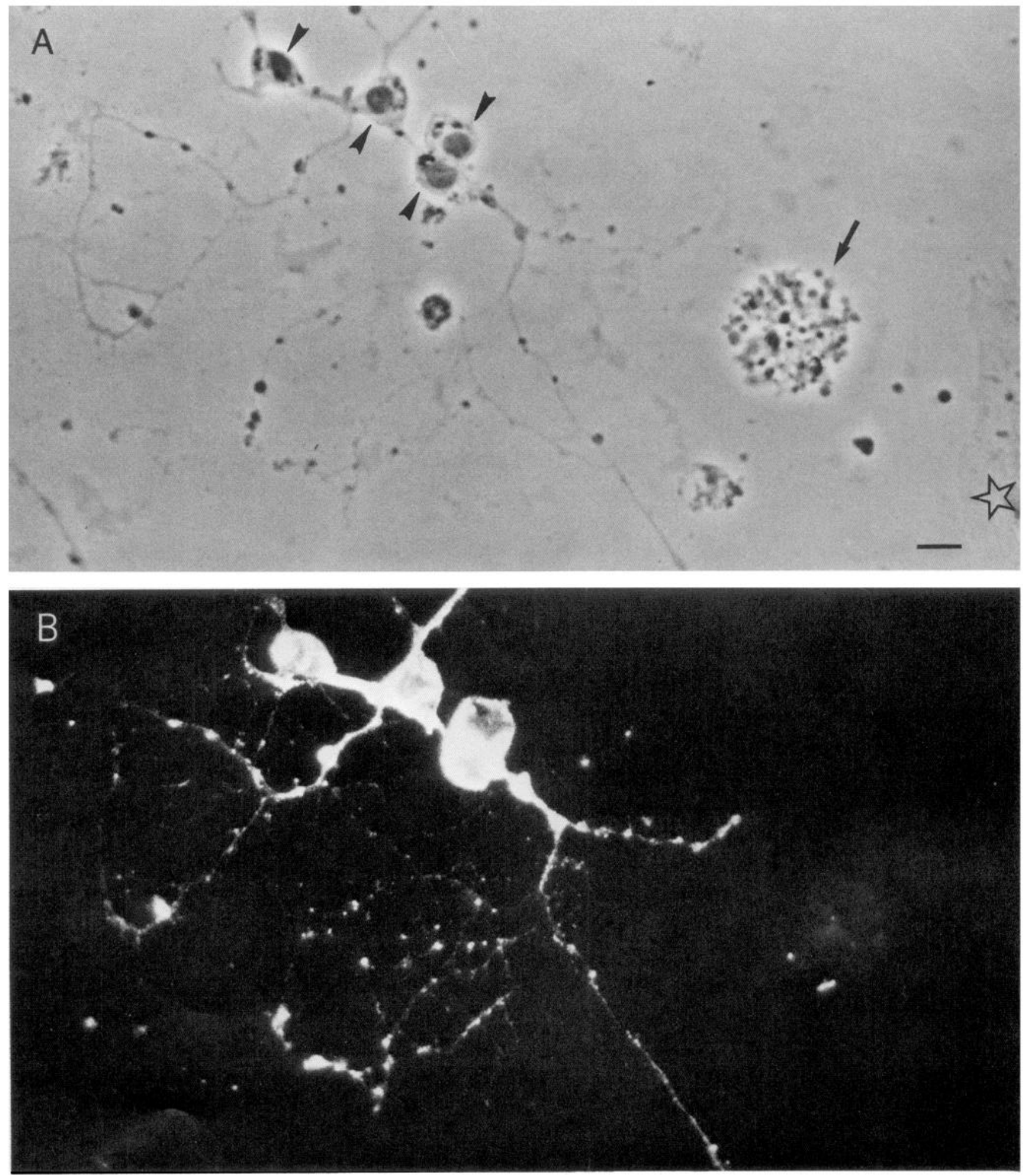

Figure 4. A, Four type-5 cells (somata marked by arrowheads) with fine processes. A large type- 2 cell with many granular inclusions (arrow) and part of a lamellipodia-forming type-3 cell (star) can be seen to the right. The cells had been kept in vitro for $6 \mathrm{~d}$ before they were fixed with $4 \%$ formaldehyde and processed for OSA immunocytochemistry with rhodamine-coupled secondary antibody. $B$, The same cells as in $A$, observed with rhodamine-fluorescence optics. OSA stains the somata and processes of type-5 cells. Only the surface membranes are stained. Note that the type- 2 and type- 3 cells are not stained. Scale bar, $10 \mu \mathrm{m}$. 

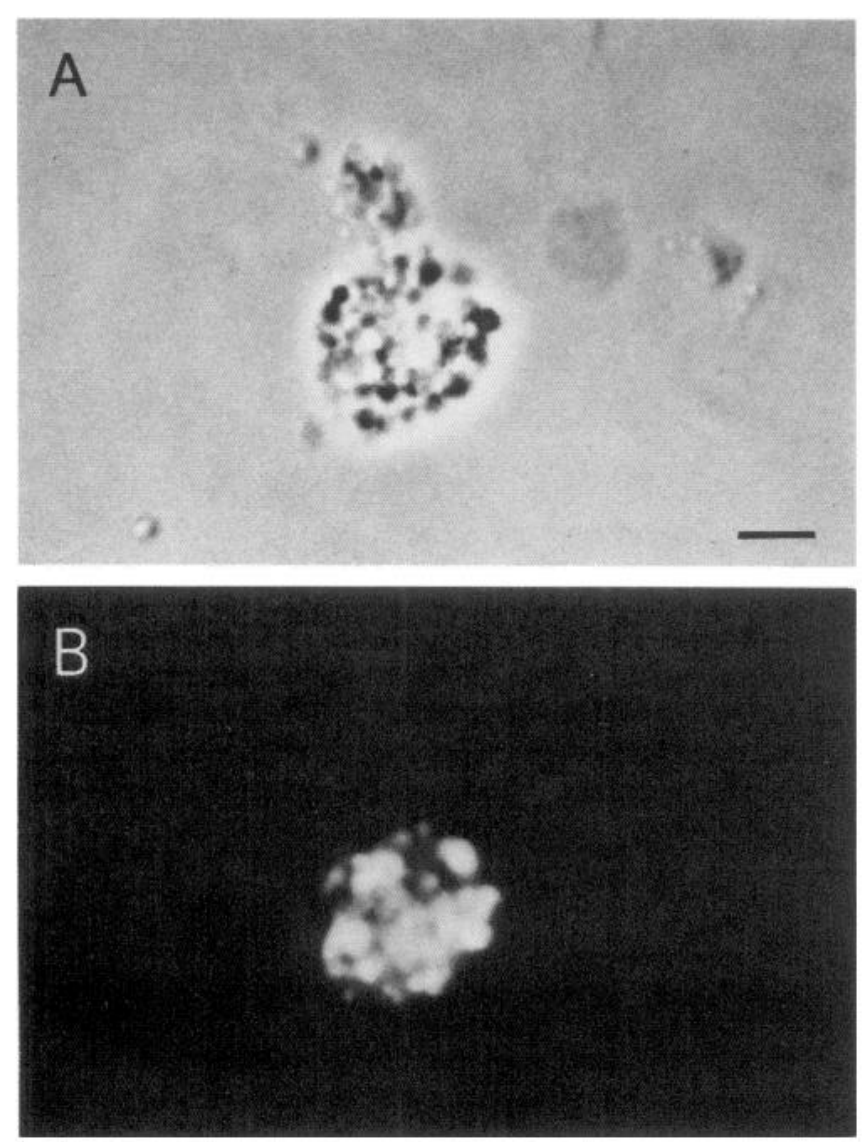

Figure 5. After $3 \mathrm{~d}$ in vitro, this type- 2 cell $(A)$ was fixed and processed for MOSA immunocytochemistry. It contains many granular inclusions, some of which are MOSA-immunoreactive (in $B$ ). The demonstration of MOSA immunoreactivity depends on the addition of Triton X-100. MOSA immunoreactivity in this type of cell appeared after $1 \mathrm{~d}$ in vitro and could still be detected (but more faintly and in fewer cells) in 4-weekold cultures. Scale bar, $10 \mu \mathrm{m}$.

OSA-immunoreactive (Fig. 7, $A-C$ ). After 4 weeks in vitro, 35$55 \%$ of the type- 5 cells with a soma diameter of ca. $6 \mu \mathrm{m}$ within one culture dish that were OSA-immunoreactive also exhibited significant but variable MOSA immunoreactivity.

Negative controls (see Materials and Methods) showed no significant staining with OSA or MOSA, except for clumps of neuropil observed in antennal-lobe cultures within a few days after plating, which were OSA-immunoreactive.

\section{Discussion}

As a first step toward experimental studies of the mechanisms and development of transduction processes and membrane excitability in insect ORNs, we have developed procedures for long-term primary culture of cells from antennae of stage- $2 \mathrm{M}$. sexta male pupae. The resulting cultures contain dispersed ORNlike cells that are easily accessible for electrophysiological studies (Stengl et al., 1989). The selective expression of 2 olfactorymarker antigens, recognized by the monoclonal antibodies OSA and MOSA, in cells with fine processes (type- 5 cells) suggests that many immunoreactive type- 5 cells are male-specific ORNs.

Although culture conditions were selected to favor the survival and growth of type- 5 cells, the cultures were kept heterogeneous because ORN-like cells survived longer in high-density cultures that contained several other cell types. Some of the types of cells observed in vitro showed signs of differentiation and could be correlated with different cell types in the antennal flagellum.

\section{Type-1 cells}

The appearance of type- 1 cells suggests that some of them might be granular hemocytes, which are thought to serve phagocytic or nutritional functions in the developing insect antenna (Jones, 1956, 1962; Whitten, 1964; Lea and Gilbert, 1966). Nevertheless, the facts that type- 1 cells are very common in our cultures and that they resemble the most numerous cells in the outermost layer of the developing flagellum suggest that most of these cells are undifferentiated epithelial cells. The dark deposits that could be formed in cells comprising these and other types of antennal cells may indicate the synthesis of cuticle after only $5 \mathrm{~d}$ in vitro, while formation of cuticle in situ starts at pupal stage 10. This suggests that some of the cells forming a cluster in vitro might differentiate into hypodermal cells earlier than they would in situ. This idea could be pursued further by electron microscopy.

The round type- 1 cells that start to form "hairs" are likely to be differentiating trichoid cells that form the hairshaft of the antennal sensilla and to which ORNs attach in situ as well as in vitro.

\section{Type-2 cells}

The appearance of type- 2 cells and their ability to adhere to dying cells in vitro suggest that these cells are also hemocytes, perhaps "spherule cells" (Jones, 1956, 1962). We could not distinguish whether type- 2 cells adhere only to cells that are already dying or can attach to and lyse viable cells. In future studies, time-lapse photography should provide more insight into the function of these cells.

Because they can be stained with MOSA after only $1 \mathrm{~d}$ in vitro and because of morphological resemblance, the type- 2 cells might be identical to MOSA-immunoreactive cells found in the lumen of the early pupal antenna (Hishinuma et al., 1988b). In situ these cells multiply and form clusters from $3 \mathrm{hr}$ after the larvalpupal molt until about stage 4 (4- to 7-d-old pupae). Over the same period, MOSA immunoreactivity develops until all of these aggregated cells express it. By stage 7 (about 7- to 15-dold pupae), these cells have lost their MOSA immunoreactivity, and the cells disappear by stage 16 (which occurs 16-22 d after the larval-pupal molt) of adult development (Hishinuma et al., 1988b). As could be demonstrated in situ, during the first week in vitro these cells also appear to be present in high numbers and to aggregate. During the first few days in culture the MOSA immunoreactivity (both the intensity of staining and the number of stained type- 2 cells) increases, until all cells of this type are stained. After 3-4 weeks in vitro, only a few type- 2 cells can be found in the cultures, and only a few of them express even faint MOSA immunoreactivity. In summary, the development of MOSA immunoreactivity and its typical granular staining pattern in vitro resemble the in situ findings, but the disappearance of MOSA immunoreactivity may be delayed in vitro.

\section{Type-3 cells}

The lamellipodia-forming, flat type- 3 cells that allow adhesion of type- 1 and 5 cells in vitro also contact these cell types in situ (not illustrated). Type- 3 cells may serve as an adhesive substrate for other cells in the antenna in situ and may be necessary for the 3-dimensional shaping of the developing antennal flagellum. The morphology of some type- 3 cells closely resembles that of plasmatocytes (Jones, 1956, 1962; Whitten, 1964). Plasmato- 

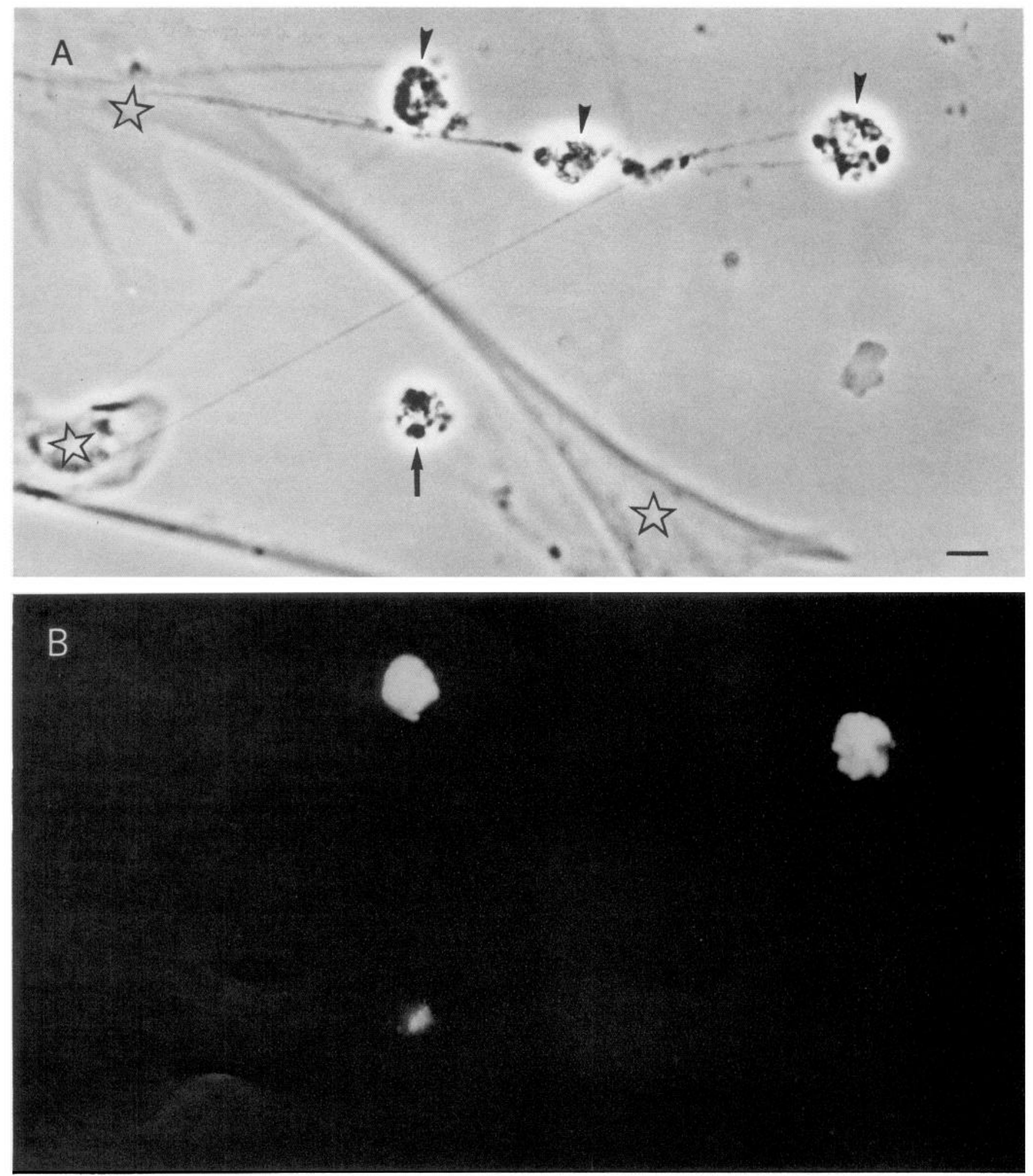

Figure 6. A, This culture was fixed after $18 \mathrm{~d}$ in vitro and processed for MOSA immunocytochemistry with rhodamine-coupled secondary antibor The somata of the 3 type- 5 cells with fine processes (arrowheads) lost their smooth appearance because of the fixation. A type- 2 cell is marked with an arrow. Type- 3 cells (stars) are shown in the background. B, MOSA recognized only 2 of the type- 5 cells and the type-2 cell. In the type- 2 cell, MOSA immunoreactivity was much weaker than that in the 2 type- 5 cells. Demonstration of MOSA immunoreactivity in type- 2 , as well as in type-5, cells depends upon the use of Triton X-100. Scale bar, $10 \mu \mathrm{m}$. 

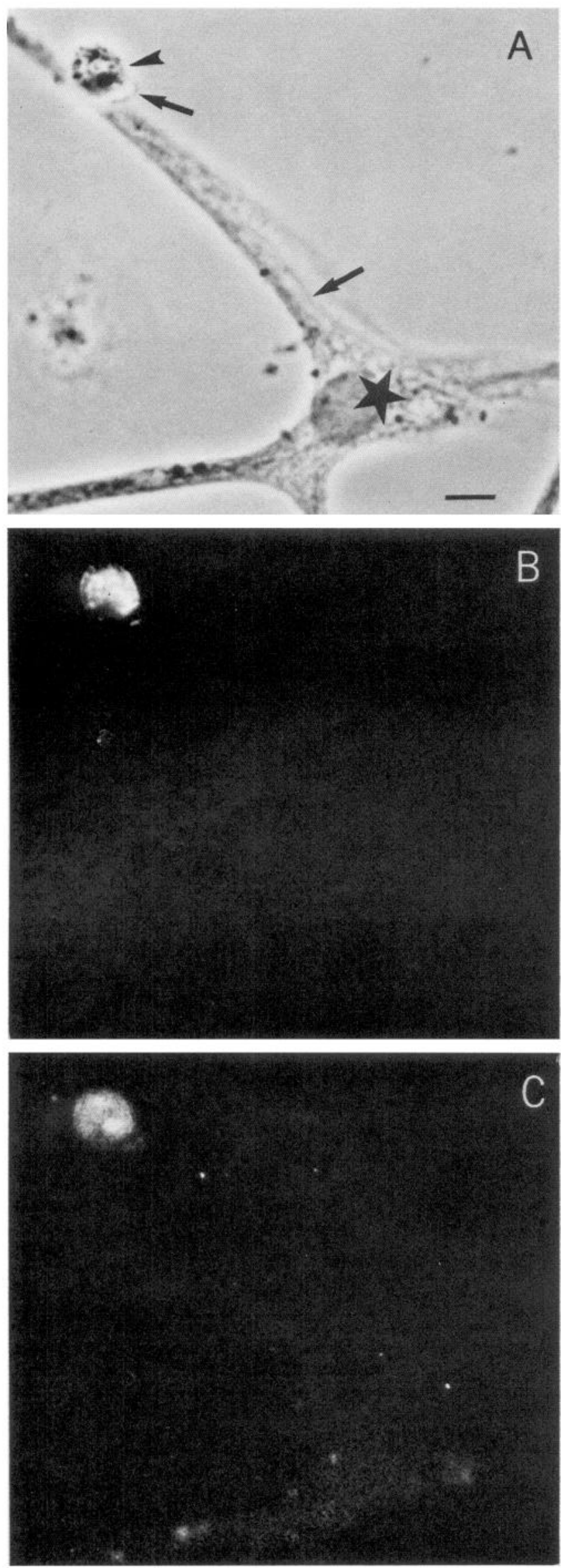

cytes play an important role in wound healing as stimulators of growth of the epidermal cells to which they attach (Clark and Harvey, 1965; Bohn, 1975). Other type-3 cells in vitro closely resemble insect epidermal cells attached to and stretched between plasmatocytes (Bohn, 1975) (Fig. 2A).

\section{Type-4 cells}

The type- 4 cells with thick processes could not be correlated with any cell type in situ because they could not be followed during the dispersion of the intact flagellum.

\section{Type-5 cells}

Most of the type- 5 cells with fine processes can be identified as ORNs by virtue of their OSA immunoreactivity (Fig. 4, $A, B$ ). In situ OSA immunoreactivity appears $70 \mathrm{hr}$ after the larvalpupal molt (corresponding to late stage 3 of pupal-adult development) and continues to be expressed throughout the rest of pupal and adult development (Hishinuma et al., 1988b). In cultures derived from late stage- 2 male $M$. sexta, OSA immunoreactivity can be detected in some cells of type 5 after $1 \mathrm{~d}$ in vitro and in $\geq 80 \%$ of type- 5 cells after $2 \mathrm{~d}$ in vitro. OSA immunoreactivity remains at a comparably high level in type- 5 cells after 4 weeks in vitro, which agrees well with findings in situ. These percentages might not accurately reflect the proportion of OSA-immunoreactive type- 5 cells in the antenna, however, because these cells have high affinity for each other and adhere to one another during the centrifugation steps. This clumping results in a highly variable yield of type- 5 cells in each culture dish. In situ as in vitro, OSA recognizes a membraneassociated antigen in the soma and processes. In situ, axons but not dendrites are stained, while in vitro most of the processes are stained by the antibody. We could not distinguish between fine processes that were truly nonimmunoreactive and ones whose fluorescent label had been bleached. Future EM studies should reveal which of the fine processes in vitro are correlated with axons or dendrites in situ. The OSA immunoreactivity observed in round cells with a soma size similar to that of type- 5 cells suggests that ORN-like cells in culture can express the OSA antigen without first having to develop processes. The OSAimmunoreactive neuropilar structures in control experiments using antennal-lobe cultures may be the terminals of ORNs. ORNs are known to terminate in dense, glomerular arborizations in the antennal lobes of $M$. sexta. The fact that not all type- 5 cells are OSA-immunoreactive suggests that type- 5 cells correspond to many or all sensory neurons of the antenna, perhaps including mechano-, thermo-, hygro-, and chemoreceptors. The proportions of receptor cells of the different sensory modalities in the antenna are not known for M. sexta. Nevertheless, most of the antennal sensilla appear to be olfactory (Sanes and

Figure 7. To test whether OSA recognized all MOSA-immunoreactive type- 5 cells in vitro as it does in situ, double-labeling experiments with rhodamine-conjugated OSA and FITC-conjugated MOSA were carried out. $A$, This 4 -week-old culture shows a type- 5 cell body (arrowhead) with fine processes (arrows). The long processes of this cell grew along a type- 3 cell (star), which had processes lying out of the focal plane of the soma. $B$, The same field as in $A$, but photographed with rhodamine optics, showing that the type- 5 cell exhibited rhodamine fluorescence and hence was OSA-immunoreactive. $C$, The same field photographed with FITC optics demonstrates the MOSA immunoreactivity of the same type- 5 cell. The type- 3 cell shows only background staining. Scale bar, $10 \mu \mathrm{m}$. 
Hildebrand, 1976a), which corresponds well with the high frequency of OSA-immunoreactive cells in vitro. Moreover, the relative abundance of sexually dimorphic olfactory hairs on the male flagellum is consistent with the finding that many OSAimmunoreactive cells are also immunoreactive to MOSA in vitro (Boeckh et al., 1960; Schneider et al., 1964; Sanes and Hildebrand, 1976a; see also reviews by Altner and Prillinger, 1980; Kaissling, 1987).

Colocalization of MOSA and OSA antigenicity in the same cells strongly suggests that those type- 5 cells are pheromoneresponsive ORNs that would innervate the trichoid sensilla in the male antenna. In situ MOSA immunoreactivity appears in those male-specific ORNs at stage- 17 of adult development. about $2 \mathrm{~d}$ before eclosion. The late expression of MOSA immunoreactivity in vitro (after 2-3 weeks in culture) correlates well with the findings in situ. Moreover, in vitro as in situ, MOSA recognizes a cytoplasmic antigen that is located in the soma as well as in all of the processes of the ORNs. However, both the initial development of MOSA immunoreactivity in type- 5 cells and the number of MOSA-immunoreactive cells seem to vary more in vitro than in situ. This variation may be due to inappropriate levels of 20-hydroxyecdysone or failure to control an unknown factor that influences the expression of the MOSA antigen.

In silu, $M$. sexta ORNs can differentiate in the absence of their normal targets (Sanes et al., 1976). Complete olfactory sensilla as well as single ORNs have already been isolated successfully from the epithelium of developing silkmoth antenna (Keil, 1987) and remain morphologically intact for at least $4 \mathrm{hr}$. The present study demonstrates that isolated ORNs from late stage- 2 pupal antennae survive more than a month in vitro and show signs of normal differentiation in long-term cultures. This opens the way for electrophysiological analysis of the membrane properties of the ORNs and more detailed studies of their differentiation.

\section{References}

Altner, H., and L. Prillinger (1980) Ultrastructure of invertebrate chemo-, thermo-, and hygroreceptors and its functional significance. Int. Rev. Cytol. 67: 69-139.

Bell, R. A., and F. A. Joachim (1976) Techniques for rearing laboratory colonies of tobacco hornworms and pink bollworms. Ann. Ent. Soc. Am. 69: 365-373.

Boeckh, J., K.-E. Kaissling, and D. Schneider (1960) Sensillen und Bau der Antennengeißel von Telea polyphemus. Zool. Jb. Anat. 78: 559-584.

Bohn, H. (1975) Growth promoting effect of haemocytes on insect epidermis in vitro. J. Insect Physiol. 21: 1283-1293.

Clark, R. M., and W. R. Harvey (1965) Cellular membrane formation by plasmatocytes of diapausing cecropia pupae. J. Insect Physiol. 11: 161-175.

Eide, P. E., J. M. Caldwell, and E. P. Marks (1975) Establishment of two cell lines from embryonic tissue of the tobacco hornworm, Manduca sexta (L.). In Vitro 11: 395-399.

Hayashi, J. H., and J. G. Hildebrand (1988) Voltage-gated currents in insect central olfactory neurons in primary culture. Soc. Neurosci. Abstr. 14:380.

Hayashi, J. H., and J. G. Hildebrand (1990) Insect olfactory neurons in vitro: Morphological and physiological characterization of cells from the developing antennal lobes of Manduca sexta. J. Neurosci. 10: 848-859.

Hishinuma, A., S. Hockfield, R. McKay, and J. G. Hildebrand (1988a)

Monoclonal antibodies reveal cell-type-specific antigens in the sex- ually dimorphic olfactory system of Manduca sexta. I. Generation of monoclonal antibodies and partial characterization of the antigens. J. Neurosci. 8: 296-307.

Hishinuma, A., S. Hockfield, R. McKay, and J. G. Hildebrand (1988b) Monoclonal antibodies reveal cell-type-specific antigens in the sexually dimorphic olfactory system of Manduca sexta. II. Expression of antigens during postembryonic development. J. Neurosci. 8: 308315.

Jones, J. C. (1956) The hemocytes of Sarcophaga bullata Parker. J. Morphol. 99: 233-257.

Jones, J. C. (1962) Current concepts concerning insect hemocytes. Am. Zool. 2: 209-246.

Kaissling, K.-E. (1987) R. H. Wright Lectures on Insect Olfaction, Simon Fraser University, Burnaby, BC, Canada.

Kaissling, K.-E., J. G. Hildebrand, and J. H. Tumlinson (1989) Pheromone receptor cells in the male moth Manduca sexta. Arch. Insect Biochem. Physiol. 10: 273-279.

Keil, T. A. (1984) Reconstruction and morphometry of silkmoth olfactory hairs: A comparative study of sensilla trichodea on the antennae of male Antheraea polyphemus and Antheraea pernyi (Insecta, Lepidoptera). Zoomorphol. 104: 147-156.

Keil, T. A. (1987) Structure of isolated sensilla and sensory neurons in vitro: Observations on developing silkmoth antennae. Cell Tissue Res. 250: 543-549.

Keil, T. A. (1989) Fine structure of the pheromone-sensitive sensilla on the antenna of the hawkmoth, Manduca sexta. Tiss. Cell 21:139151.

Keil, T. A., and R. A. Steinbrecht (1984) Mechanosensitive and olfactory sensilla of insects. In Insect Ultrastructure, Vol. 2, R. C. King and $\mathrm{H}$. Akai, eds., pp. 477-516, Plenum, New York.

Keil, T. A., and R. A. Steinbrecht (1987) Diffusion barriers in silkmoth sensory epithelia: Application of lanthanum tracer to olfactory sensilla of Antheraea polyphemus and Bombyx mori. Tiss. Cell 19: 119-134.

Lea, M. S., and L. I. Gilbert (1966) The hemocytes of Hyalophora cecropia (Lepidoptera). J. Morphol. 118: 197-216.

Sanes, J. R., and J. G. Hildebrand (1976a) Structure and development of antennae in a moth, Manduca sexta. Dev. Biol. 51: 282-299.

Sanes, J. R., and J. G. Hildebrand (1976b) Origin and morphogenesis of sensory neurons in an insect antenna. Dev. Biol. 51: 300-319.

Sanes, J. R., J. G. Hildebrand, and D. J. Prescott (1976) Differentiation of insect sensory neurons in the absence of their normal synaptic targets. Dev. Biol. 52: 121-127.

Schneider, D., V. Lacher, and K.-E. Kaissling (1964) Die Reaktionsweise und das Reaktionsspektrum von Riechzellen bei Antheraca pernyi (Lepidoptera, Saturniidae). Z. Vergl. Physiol. 48: 632-662.

Schweitzer, E. S., J. R. Sanes, and J. G. Hildebrand (1976) Ontogeny of clcctroantennogram responses in the moth Manduca sexta. J. Insect Physiol. 22: 955-960.

Starratt, A. N., K. H. Dahm, N. Allen, J. G. Hildebrand, T. L. Payne, and H. Röller (1979) Bombykal, a sex pheromone of the sphinx moth Manduca sexta. Z. Naturforsch. 34C: 9-12.

Steinbrecht, R. A., and W. Gnatzy (1984) Pheromone receptors in Bombyx mori and Antheraea pernyi. I. Reconstruction of the cellular organization of the sensilla trichodea. Cell Tissue Res. 235: 25-34.

Stengl, M., and J. G. Hildebrand (1988) Immunocytochemical identification of olfactory receptor neurons from male Manduca sexta pupae in vitro. Soc. Neurosci. Abstr. 14: 379 .

Stengl, M., F. Zufall, H. Hatt, J. Dudel, and J. G. Hildebrand (1989) Patch clump analysis of male Manduca sexta olfactory receptor neurons in primary cell culture. Soc. Neurosci. Abstr. 15: 751.

Tolbert, L. P., S. G. Matsumoto, and J. G. Hildebrand (1983) Development of synapses in the antennal lobes of the moth Manduca sexta during metamorphosis. J. Neurosci. 3: 1158-1175.

Tumlinson, J. H., M. M. Brennan, R. E. Doolittle, E. R. Mitchell, A. Brabham, B. E. Mazomenos, A. H. Baumhover, and D. M. Jackson (1989) Identification of a pheromone blend attractive to Manduca sexta (L.) males in a wind tunnel. Arch. Insect Biochem. Physiol. 10: 255-271.

Whitten, J. M. (1964) Hemocytes and the metamorphosing tissues in Sarcophaga bullata, Drosophila melanogaster, and other cyclorrhaphous Diptera. J. Insect Physiol. 10: 447-469. 